\title{
A Simple Improvement on Existing Technology to Enhance Transseptal Puncture and Left Atrial Access Using Large Diameter Sheaths for Mapping, Ablation and LAA Occlusion Procedures
}

Gregory Feld ${ }^{1}$ and Jonathan $\mathrm{Hsu}^{2}$

${ }^{1}$ University of California-San Diego

${ }^{2}$ University of California, San Diego

January 20, 2021

\section{Hosted file}

Ed Comment JCE 2021 Final Draft.pdf available at https://authorea.com/users/317505/articles/ 504453-a-simple-improvement-on-existing-technology-to-enhance-transseptal-puncture-andleft-atrial-access-using-large-diameter-sheaths-for-mapping-ablation-and-laa-occlusionprocedures 